\title{
Secondary Musical Personality: Structure, Psychological Mechanism of Development
}

\author{
Irina $V$. Cheremisova* \\ Volgograd State University, Volgograd, Russia
}

\begin{abstract}
Today's socio-cultural situation requires new approaches to education. The aesthetic and semiotic approach promotes the humanization of the modern education and the development of the student's holistic creative personality by means of classical musical art. From the standpoint of the aesthetic and semiotic approach, music is understood as a complex psychosemantic text. Due to the theoretical analysis of the studies of a secondary language personality and the studies of music and speech psychological kinship, the notion of a secondary musical personality as a kind of a secondary linguistic personality has been elaborated. The author has developed the structure and disclosed a psychological mechanism for developing a secondary musical personality. This psychological mechanism was tested as part of the longitudinal study. The structure of a secondary musical personality is presented as an aggregate of musical and cognitive, motivational, emotional, communicative, pragmatist, and spiritual and moral (axiological) components. The psychological mechanism for developing a secondary musical personality is a system of interrelated conditions and factors. These conditions and factors include: the complexity, polysemy, and semantic versatility of a musical text; musical valence; the psychological mechanism of figurative verbalization, etc. Musical enculturation serves as a universal developing mechanism.
\end{abstract}

\section{Introduction}

Psychological and pedagogical theory is a peculiar strategy of psychological and pedagogical activity: it traces changes in the culture, the society's social needs and offers new solutions to the persistent problems of education, new approaches to the organization of trainees' life and activities, their attitude toward the world and to themselves. The more difficult the changes around us are, the broader rethinking of our previous theoretical concepts should be. These traditional and seemingly fundamental concepts "fall apart" in the modern sociocultural situation, giving way to new theoretical concepts that determine new approaches to education $[1,2,3,4,5,6]$.

The current period in education development is marked by the tendency to the integration of several approaches and the emergence of a new original aesthetic and semiotic approach as a methodological basis for selecting and constructing the content of education.

In the study, the aesthetic and semiotic approach is considered as a specific form to ensure the interrelation, interpenetration of person-centered, pragmatist, anthropological, cultural, synergistic, ontological, and semiotic approaches and aesthetic concepts. It is our view that this approach largely determines the substantive and procedural basis of the humanization of education; holistic view of the laws of the development of a human as a natural, social, and spiritual creature; holistic view of the content of education as a learned experience represented in the unity of values and meanings $[7,8]$.

We believe that reliance on the basic provisions of the aesthetic and semiotic approach to education will contribute to the successful accomplishment of the goals and objectives of modern education, to the development of a holistic creative personality by means of musical art.

\section{Materials and methods}

\subsection{The main categories of aesthetic-semiotic approach}

Key concepts/categories form the methodological basis of any approach. First of all, they include the general psychological category-personality. The concept of

*Corresponding author: cheremisova@ volsu.ru 
personality through the standpoint of the aesthetic and semiotic approach reflects all diverse aspects of the existence of an individual, such as, natural, social, spiritual, historical, and cosmic ones. The personality is a person that is a unique subject of acculturation and socialization.

From the standpoint of the new original aesthetic and semiotic approach, music is perceived as a complex psychosemantic text filled with universal human (national culture, style of the epoch and composer) and personal meanings. The process of finding and recognizing the meanings of different levels invokes the development of an individual's creative abilities and the formation of a creative personality as a whole, which is conditioned by the multiple values and semantic variety of a musical text $[9,10,11,12,13]$.

The development and application of the aesthetic and semiotic approach integrating philological, linguistic, pedagogical, and psychological knowledge is justified by the fact that the speech and music affinity at a brain level already emerged 8 million years ago, which, in a way, reinforces the established practice of calling music "a musical language". This is probably not just a metaphor but a psychological and even neuropsychological reality $[12,14,15,16,17,18,19]$.

\section{2. "A musical language". This is probably not just a metaphor but a psychological and even a neuropsychological reality}

The origin of the aural recall, which has been studied by B. M. Teplov [20] and is the basis of music-making for different peoples, is also associated with the linguistic and verbal specificity of sound material. The music of the people, which gave birth to its language and expressed the make-up of its soul, had its own characteristic melodic moves and its favorite motives. This music has always tended to the same intervals and at the same time behaved as if avoiding the others; the melodies of peoples and races, their songs and tunes persistently cultivated the same tunes, phrases, and momentum. Together with its speech and language, the musical speech of the people was composed: these two related types of speech greatly resembled each other. The different logic of thought gave rise to a different logic of language and speech and a different logic of sound connections showing through the music of different peoples and races.

The ideas of the psychological kinship of music and speech based on the unity of the musical and speech mechanisms of the brain could not be reflected in the concept of B. M. Teplov [20] due to the limited possibilities of neuropsychology of the mid-20th century. However, this new data denotes the ways of further researches of musical abilities and talent and the development of the musicality of a personality. If we use the analogy with speech, the analytical ear (the combination of melodic and harmonic ears in their unity) ensures the formation of music and language, music and speech competence of an individual $[16,17,18,19,21$, 22, 23].
Continuing the analogy with speech, it can be said that the possessor of highly developed analytical ear easily masters the musical language: he/she masters the phonetics - sound composition, vocabulary-typical musical constructions, motifs, themes, and grammar system - a system of sound relations and rules for textmaking of this language. The neuropsychological community of the mechanisms responsible for the flow of musical and speech activity discovered in the second half of the 20th century is a methodological key to the study of the musical and creative talent of D. K. Kirnarskaya [21].

Any fragment of music texture represents the simultaneous combination of melodic, textural and harmonic, modal, and rhythmic sides, i.e., initially, the fragment is vertically "grammatical". Thus, a musical symbol is not only linear, like a verbal language word, but also voluminous. Some researchers show that the symbolic process has extramusical prototypes: emotions, sentiments, willful cravings, views of the outside world, and so on. They are interpreted by the musical language, preserving the "signified" beyond [12, 24, 25, 26, 27, $28]$.

\subsection{Secondary linguistic identity}

Thus, assuming the speech and music affinity marked by the researchers as psychological reality, we turned to the scientific concepts of a linguistic identity $[14,29]$. There are extremely few studies of a linguistic identity on a personal and psychological level, although there are productive ideas about the structure of an individual's linguistic consciousness [15], the relationship of language, speech, and creativity of a personality [17, 18 19, 23]. The wide dissemination of a communicative approach in the professional training of experts in foreign languages is associated with the increased attention to the personal characteristics of an expert and the emergence of a secondary linguistic identity issue $[14,29]$.

\subsection{Secondary musical personality as a type of linguistic identity}

Based on the theoretical analysis of the studies devoted to a secondary linguistic identity and taking into account the ideas of the psychological relationship between music and speech, the understanding of music as a special system of relations (made of elements such as, the human, the world, and the semiotic complex-"the language of music" - that mediates their interaction) [12], we have developed the concept of and described the structure of a secondary musical personality, identified the psychological development conditions and levels, and defined the content of musical communicative competence.

The musical activity, the musical language are most closely connected to the internal world of a person, to the system of his/her values, which are implemented in communication with music and other people. According to B. M. Teplov [20], music is a means of 
communication between people; to speak music, not only a command of this language is required, but also having what to say; a person with a great spiritual, intellectual, and emotional content can be a significant musician. He writes that Rimsky-Korsakov was not only a great musician but a great man above all. In one way or another, this applies to all significant musicians: Beethoven, Schumann, Liszt, Glinka, Tchaikovsky, Mussorgsky, first and foremost, all of them were people with a richest ideological content, having much to say to mankind.

This also applies to the artists who can embody the composers' intentions through perception and creative rendering.

\subsection{Personal characteristics in the structure of musical abilities}

Personal characteristics as noted in the studies [20, 21, 25 ] are part of the structure of musical abilities and determine the level of their development as well as the level of achievements in the practice of communicating with music.

Firstly, this is due to the development of the motives for communicating with music and the desire to understand its content. Pedagogic practice shows that the level of motivation for mastering music knowledge, skills and abilities to perform and compose music is directly linked to success in music training and success in musical life. Musical life motivation is the most important and primary characteristic of a secondary musical personality.

Secondly, personal traits are part of the overall structure of musical abilities and determine success in mastering various types of musical activities, depending on the person's efficiency, perseverance, and ability to a will-tension.

Thirdly, personal qualities belong to the structure of musical abilities and determine the success of musical and creative activity through the individual style of musical and performance activity, individual opportunities for communicating with music during musical perception, the individual character of personal experiences, and personal attitude towards music. Musical activity contributes to the development of the creative identity of a personality and the ability for free, open, and spiritual communication. Communication with music becomes a special and independent spiritual activity, the purpose and the meaning of which are a dialog between the listener, the composer, and the artist for the sake of spiritual enrichment. First of all, it refers to classical music. Classical music preserves and develops the possibilities of figurative expression of subtlest, intimate and secret emotional processes that are inaccessible to either verbal or scenic and TV embodiment $[8,16,30,31,32]$.

Understanding between people while interacting, including the understanding of musical speech, essentially depends on the psychological, spiritual community of people, who are entering into communication, and is determined by a person's ability to be attuned to another person, in other words to "feel" an interlocutor. There are many significant examples of the manifestation of such an ability, described both in scientific and psychological, and especially, fiction literature.

To truly understand another person who speaks a musical language and to achieve genuine understanding with him/her can only be in the context of a real dialog, which is, in the words of M.A. Kurilovich [33], a cobeing with this other. Only the one who possess the qualities of a dialogical personality or, at any rate, who wants to be such a person can be in a genuine dialog with another person. The process of the perception of a musical composition promotes the development of dialogical communication between the subjects of an educational process. When listening to music, they enter into a dialog particularly with music, and through it, with the composer, who wrote this music, and the performer, who created his/her own rendition.

\section{The structure of a secondary musical personality}

\subsection{The main components of the structure of the secondary musical personality}

Within our work, musical abilities (musical sense, musical consciousness, musical thinking) are considered as the system component of an integrated personality, as the basic integrated component of a secondary musical personality. The analysis of the available studies makes it possible to single out the following main components in the structure of a secondary musical personality.

\subsubsection{The musical and cognitive component of the structure of a secondary musical personality}

The musical and cognitive component of the structure of a secondary musical personality combines the properties and abilities characterizing the individual characteristics of the psychical cognitive processes ensuring musical and creative activity. In addition to this, it can include the general cognitive and musical features of a personality, characterizing the individual musical view of the world, the system of necessary knowledge (the history of musical art, knowledge of the means of musical expressiveness, musical styles and genres, composers and performers, the content of musical concepts, the features of a musical language, musical culture, etc.).

\subsubsection{The motivational component of the structure of a secondary musical personality}

The motivational component of the structure of a secondary musical personality particularly combines a system of motives and positive attitudes: the need to listen to music and to engage in musical creativity, to engage in a favorite kind of creativity under the influence of music; motivation for human higher needs, 
self-realization and self-actualization, self-improvement. In recent years, the attention of scientists to the musical needs of listeners has significantly increased [8, 11, 21, $25,27]$. Here, the set of the intrinsic motives of musical activity expressing a person's individual orientation in the system of musical art has a particular importance.

We assume that the motivational component rests upon the dominant type of motivational attitude of musical activity as well as the prevailing ethnic and cultural orientation of a secondary musical personality $[12,26]$.

\subsubsection{The emotional component of the structure of a secondary musical personality}

The emotional component of the structure of a secondary musical personality is represented by a combination of properties and abilities expressing the emotional and sensitive side of musical and creative activity. As can be followed from the analysis of numerous publications, the emotional component can comprise emotional and value motives for the perception, performance, composing of music, motives for mastering a musical language; motives expressing immediate emotional experience in the process of musical activity; the prevailing ways of expressing emotional states and experiences associated with the content of music interaction; the individual repertoire of musical expressiveness aids, abilities, skills, and practices to perform and compose music; the presence or absence of extramusical phenomena in the process of music perception by a secondary musical personality. [13, 24, 27, 28, 34].

The research of the peculiarities of the emotional sphere of musicians with different levels of musical sense $[25,35,36]$ has showed that the average musician can be described as more empathic, possessing the ability to the more adequate recognition of emotions. It was noted that the increase in the musical sense level of the subjects corresponds to a reliable increase in the expression in their state of emotions associated with the state of mental equilibrium. On the contrary, the evidence of negative experiences with the growth of musical sense is reliably reduced.

\subsubsection{The communicative component of the structure of a secondary musical personality}

The communicative component of the structure of a secondary musical personality combines the individual characteristics of a personality, ensuring his/her participation in the spiritual communication through musical art means. They are most fully represented in the model of musical abilities described above and constitute the psychological basis of the structure of a musical personality. The communicative component, in turn, is a structure in which the motivational, emotional, cognitive, operational, and other components can be distinguished as its part [32, 37, 38, 39, 40]. As integral manifestations of this interconnected set of communicative properties and abilities of a secondary musical personality, the following can be considered: empathy as an affective and cognitive component of communication and mutual understanding [32]; personal communicative tolerance [37]; capacity for multicultural dialog [26].

\subsubsection{The pragmatist component of the structure of a secondary musical personality}

The pragmatist component of the structure of a secondary musical personality combines the psychological features of the individual and personal style of musical and creative activity. First of all, the study of the individual style of activity is worth mentioning. The psychological analysis of the art style issues, undertaken in the works of Kagan\&Kirchberg [13], L.N. Popov [34], Taraeva [10] is of particular interest to our study; the research of the features of the "artistic" and "mental" manifestation in the emotional style of artistic creativity carried out by Kirnarskaia D. K. [21] is of special interest, too. The importance of the studies by Knyazeva, T. S. [36], who revealed the influence of psychological types of personality on musical activity and music training, should be also emphasized.

\subsubsection{The spiritual and moral (axiological)} component of the structure of a secondary musical personality

The spiritual and moral (axiological) component of the structure of a secondary musical personality integrates the system of formed moral concepts, value orientations, and moral and spiritual significances of a personality.

Several thesis studies have verified the powerful, spiritual potential of truly dialogical communication, optimizing the teaching and development. In these studies, the signs of a dialog as a higher, personal, and spiritually oriented level of communication were identified and analyzed [33, 37, 41]. The basic characteristics of dialogical communication simultaneously act as the features of a dialogical musical personality which embodies dialog spiritual potentials.

From the standpoint of the aesthetic and semiotic approach, axiological and moral orientations in the structure of a secondary musical personality are the determining factor of its development.

\subsection{The definition of a secondary musical personality}

Therefore, all the qualities considered above within the general structure of a personality and in the process of musical and creative activity describe a secondary musical personality.

In our research, a secondary musical personality is defined as a musically and creatively active entity able to discover, describe, evaluate, and change the surrounding reality and own musical and creative environment as well as to interact with music and other people through musical art in the process of musical activity. 


\section{The results of the study}

\subsection{Development of secondary musical personality at different levels of education}

The development level of musical consciousness, the level of musical and language, musical and verbal, and musical communicative competence depend on the development level of properties and abilities forming the psychological structure of a secondary musical personality [21, 25, 35, 36, 42, 43].

Our study is committed to the creation of a conceptual psychological model for the development of a creative personality through musical art (secondary musical personality). However, taking into account its practical orientation, we deem it appropriate to show how this model fits into the educational system at different levels of: mass music education, musical dual education, musical specialized tertiary education.

Based on the conclusions of the theoretical study, we determine the development levels of musical sense, depending on the length of musical activity. The longer musical activity continues, the higher the level of musical sense becomes and, therefore, the higher the level of musical and creative development of a personality, a secondary musical personality in the aggregate of all components: musical and cognitive, motivational, emotional, communicative, activity, spiritual and moral (axiological) components.

Thus, engaging a trainee, a student in a mass music education (pre-school educational institution, secondary school, institution of vocational secondary education, university, self-education) implies the achievement of the highest level of a secondary musical personality at the stages of the senior grades of secondary school and, accordingly, at higher levels of education. Dual musical education (music school, music college), higher special musical education (musical institute, conservatory) create a full range of conditions for achieving the level of a secondary musical personality. We should especially emphasize that successful creative personal development (by means of musical art) and the achievement of a secondary musical personality level are possible within mass music education.

\section{The psychological mechanism of development of secondary musical personality.}

Based on this definition, within the framework of our research, under the psychological mechanism of the development of a creative personality by means of musical art, we will understand the system of various factors, conditions, means, relationships, connections and other mental phenomena.

\subsection{Approbation of the psychological mechanism}

In order to indicate the main components of this mechanism and to construct its hypothetical model, we carried out a longitudinal study for 10 years to reveal the development process of a creative personality by means of musical art in preschool children, their teachers, and senior teachers (preschool institutions of Nizhny Novgorod and Nizhny Novgorod Oblast), schoolchildren and their teachers (secondary schools of Nizhny Novgorod, Nizhny Novgorod Oblast, Vladimir Oblast), college and university students and their teachers (N. A. Dobrolyubova State Linguistic University of Nizhny Novgorod, Nizhny Novgorod Branch of the Institute of Business and Politics, Volgograd Institute for the Humanities VolGU).

\subsection{The main components of this mechanism}

\subsubsection{Musical enculturation}

The analysis of the observation results and the review of literature allow proposing the hypothesis that the psychological mechanism for creative personality development by means of music art is a system structure including several psychological components.

I. M. Kyshtymova [44], has investigated the issue of schoolchildren creativity development from the standpoint of a psychosemiotic approach. She states that creativity is a personality trait showing itself in the implementation of personal meaning by the medium of culture, that the creative act is characterized by the procedural ambivalence of freedom and limitation, the transcendental infinity and limitations set by culture, unconscious non-obviousness and real objectivity, sense continuity and semiotic system discreteness, that the creative act includes the stage of acquiring personal meaning and the stage of its symbolic objectification. Kyshtymova introduces the concept of "tuning-fork culture", which transmits the ideal values and representations reflected in meaningful texts. In our study, the classic music art acts as a "tuning-fork culture". The texts of the tuning-fork music culture are classical musical works. Based on the findings of I. M. Kyshtymova [44], we can conclude that the psychosemiotic structure of musical educational space, homomorphic to the structure of the tuning-fork music culture, has a positive impact on the development of creativity; the main pragmatic characteristic of creative educational space is a dialog, the semantic one is higher semantic levels (spiritual, national-cultural, humanistic), the syntactic one is ethics, aesthetics, philosophy, and religion.

The tuning-fork musical culture contains the attitudes of four worldview semantic levels: domestic, social, ethnical, and spiritual. The richer the value interiorization of the tuning-fork musical culture are, the more semantic alternatives, options of individual choice of free behavior repertoires appear. To a large extent, the degree of musical enculturation determines the level of creativity; in the musical culture, the formation of a creative personality takes place.

Thus, the approach to the musical culture as a 
secondary semiotic system allowed to systematically consider the mechanism of conditioning the actualization of creativity. A universal development mechanism is musical enculturation.

The analysis made it possible to conclude: the psychological development mechanism of a secondary musical personality by means of musical art is a system of interrelated conditions, factors ensuring the optimization of this process. These include: complexity, polysemy, and semantic versatility of musical text; modeling during musical perception creative process (mental experiment in musical activity); psychical phenomenon of the synaesthesia of musical and artistic consciousness; polymodality of musical perception; symbolism in music, archetypes of musical consciousness and their interaction; connotations in music; psychological mechanism of figurative verbalization; psychological mechanism of empathy, compassion, co-creation during musical perception; psychological and psychophysiological mechanisms of music therapy, art therapy, and therapy of creative selfexpression; unified psychophysiological mechanisms of creative and musical ability development; musical enculturation serves as a universal developing mechanism [13, 28, 31, 38, 44, 45, 46, 47].

Within the framework of this article, we will pay attention to the psychological mechanism of connotations in music and figurative verbalization.

\subsubsection{The connotation in music is the psychological development mechanism}

The connotation in music is the psychological development mechanism of musical and artistic consciousness and a secondary musical personality as a whole.

In his study, L. N. Popov [34] used an approach to the process of developing a creative personality, based on additional, connotative meanings of the author's text. Popov identified the role and significance of connotations in a musical language and speech as a phenomenon and a means which contribute to the development of artistic consciousness. He also explained the use of connotations in music teaching methods as an approach to understanding (performing, listening to) the author's text. Popov highlighted a special component in a musical work as an art object, in its inner form. That component is a connotation. Popov also defined and described its structure (i.e., emotional, rational, stylistic, and figuratively associative and artistically figurative components), properties (i.e., uniqueness, mobility, diversity, integrity, etc) and functions: (semantic, communicative, clarifying, heuristic). He introduced a new concept of "musical connotation"- the unique integral meaning of a musical work-additional (performer's and listener's) meanings of the author's musical text, determined the indicators of the level of development of artistic consciousness (emotional, emotional and intellectual, artistic and figurative understanding), the development levels of the artistic consciousness of a child at the upper end of the preschool age range (superficial, deep, and creative).

In the context of our research, the position of $\mathrm{L}$. Yelmslev [48] about the sphere of connotative semiotics is of great interest. He included a wide range of phenomena, which are also manifested in a musical text, to this sphere. The difference of stylistic forms (within our study, these are musical genres), by which Yelmslev [48] meant verse, prose, and various mixed forms, the difference of evaluative high and low styles (within our study, these are classical and light music), the difference of emotional connotations, parlances, professional jargon, and slang (academic musical art, folk musical art), the difference of national and regional languages and even individual differences in pronunciation (peculiarities of music performance).

\subsubsection{The psychological mechanism of figurative verbalization}

In the process of developing a creative personality, it may be legitimate to use the psychological mechanism of figurative verbalization.

The scientific study by L. A. Shestak [47] presents the justification and description of the mechanism of figurative verbalization, which produces metaphors of different nature and complexity levels (verbal, textual, subject-symbolic). Shestak represents figurative verbalization as a mental mechanism of perceiving one object through its real or simulated similarity with another object. He also represents an image as a cognitive device for learning reality by comparing it with another reality, an image as an artistic device of expressiveness, as a mechanism for creating the micro(detail) and macro- (text) phenomena of multidimensional meaning.

\section{Discussion and conclusion}

The basic provisions of the aesthetic and semiotic approach, the conclusions about the psychological conditions and psychological mechanisms of developing a creative personality by means of musical art allowed to justify the notion of a secondary musical identity as a variety of a secondary linguistic identity, to develop and present the structure and psychological mechanism of developing a secondary musical personality in the space of modern mass and special musical education. The results of the research make it possible to optimize the development process of a creative personality in the educational process, increasing its effectiveness.

\section{References}

1. D.Y. Feldman, M. Chikszentmihalyi, H. Gardner, Changing the world: A framework for the study of creativity, (Yale Press, Yale, 1994)

2. H. Gardner, Creative lives and creative works: A synthetic scientific approach, (Cambridge University Press, New York, 1988) 
3. C.R. Rogers, On Becoming a Person. (Constable, Boston, 1961).

4. M.G. Reznichenko, Pedagogical Education and Science, 8, 32-42 (2009)

5. Iu.P. Zinchenko, National Psychological Journal 1 (3), 86-89 (2010)

6. O.V. Inshakov, O.Yu. Redkina, Science Journal of Volgograd State University. History. Area Studies. International Relations 21 (3), 150-161 (2016)

7. E.P. Torrance, Education and Creative Potential (Personnel press, Minneapolis, 1963)

8. I.V. Cheremisova, European Journal of Multidisciplinary Studies 4(1), 78-87 (2017)

9. A.R. Rafikova, Semantics musical text: philosophical analysis, PhD. Philosophy sci. diss. (Chuvashskiy State University, Cheboksary, Russia, 2006)

10. G.R. Taraeva, Semantics of the musical language: conventions, traditions, interpretations (Art-transit, Moscow, 2012)

11. S.O. Vyshegorodtseva, Historical analysis of the development of music psychology in the XX century (Tipografiya MGPU, Moscow, 2001)

12. T.A. Ryzhkova-Dudonova, Music in the context of the cultural picture of the world, $\mathrm{PhD}$ Culturology sci. diss. (Moscow, 2005)

13. S. Kagan, V. Kirchberg, Journal of Cleaner Production 135 (1), 1487-1502 (2016)

14. N.N. Nechayev, Procedia - Social and Behavioral Sciences 154, 14 - 22 ( 2014 )

15. P.Ya. Galperin, Problems of Philosophy 4, 95-101 (1997) (in Russian)

16. T.V. Lazutina, Onto-epistemological and Axiological Basics of Music Language, Dr. philosof. sci. diss., (Ural State University, Ekaterinburg, 2009)

17. J.M. Rodd, O.A. Longe, B. Randall, L.K. Tyler, Neuropsychologia, 58(5), 1324-1335 (2010)

18. A.R. Luria, Brain and language 1(1), 1-14 (1974)

19. F. Dick, N.F. Dronkers, L. Pizzamiglio, A.P Saygin, S. L. Small, S. Wilson, Language and the brain. Beyond nature - nurture, (Essays in honor of Elizabeth Bates Erlbaum, London, UK, 2005)

20. B.M. Teplov, Psychology musical abilities. Selected Works. (Pedagogy, Moscow, 1985)

21.D.K. Kirnarskaia, Theoretical foundations and methods for evaluating of musical aptitude, Dr. ped. sci. diss. (Moscow, 2006)

22. A.V. Toropova, Homo Musicus Reflected in MusicPsychological and Musical-Pedagogical Anthropology (Academic Publishing Center GRAFPRESS, Moscow, 2008)

23. A.R. Luria, Current Trends in Linguistics 12, 25612595 (1974)

24. G.N. Kechhuashvili, Questions of Psychology 1, 2533 (1957)
25. A.V. Toropova, The phenomenon of musical consciousness: the methodology of research and development, Dr. ped. sci. Diss. (Moscow, 2009)

26. L.L. Balkwill, W.F. Thompson, Music Percept 17, 43-64 (1999)

27. T. Baumgartner, M. Esslen, L. Lutz Jäncke, Int. J. Psychophysiol 60, 34-43 (2006)

28. E.A. Medvedeva, Formation of the personality of the child with mental development problems by means of art in the artpedagogical and art-therapeutic environment, (Institute of Consulting and System Solutions, Moscow, 2009)

29. M. Bogatyreova, Procedia - Social and Behavioral Sciences, 214, 544 - 551 (2015)

30. J. Burton, R. Horowitz, H. Abeles, Leaning In and Through the Arts, (Columbia University, New York, 2008)

31. V.N. Kulbizhekov, Thought Experiment as a Basis for Modern Classical Music: Philosophical-Aesthetic Analysis, PhD. Philosophy sci. diss. (Moscow State University Moscow, 2008

32. V.V. Ryzhov, Personality, creativity, and spirituality (St. Petersburg Christian University Publ., St. Petersburg, 2012)

33. M.A. Kurilovich, The formation of dialogical interaction in educational and professional activities : the case of psychology students (YArGPU im. K.D. Ushinskogo, YAroslavl', 2008)

34. L.N. Popov, Context in music as a means of developing the artistic consciousness of the elder preschooler, PhD. Pedagogical sci. diss. (Ekaterinburg, 2003)

35. T.S. Knyazeva, A.N. Lebedev, Psychological journal 22 (6), 87-91 (2001)

36. T.S. Knyazeva, Journal of Applied Psychology 5, 3-5 (2000)

37. V.A. Ponomarenko, Psychology of spirituality professional, (RAS Ipanema, Moscow, 2004)

38. I.V. Kurysheva, The World of Science, Culture, Education 6 (25-2), 103-107 (2010)

39. E.Vorobyeva, L.Talalaeva, N. Pomazkova, A. Sokurenko, N. Samoilova, Procedia - Social and Behavioral Sciences, 146, 483-486 (2014)

40. H.J. Eysenck, Psychology Inquiry 4, 147-178 (1993)

41. G. Ekvall, A. Britz, Creativity Research Journal 13 (2), 171-184 (2001)

42. C.E. Seashore, Psychology of Music. (Gemünder, New York, 1990)

43. K. James, Ch. Asmus,, Creativity Research Journal 2, 149-159 (2000)

44. I.M. Kyshtymova, Psychosemiotics of Creativity (Publishing house of Irkutsk State University, Irkutsk, 2008)

45. N.P. Kolyadenko, Musical and aesthetic education: Synesthesia and the combined effect of the Arts 
(Publishing house of Novosibirsk State Conservatory named after M. I. Glinka Novosibirsk, 2003)

46. E.A. Kuznetsova, History of the study of the phenomenon of synesthesia, (OOO Pechatnyj dvor, Kazan', 2005)

47. L.A. Shestak, Russian language personality: codes of figurative verbalization of the thesaurus, Dr. Philol. sci. diss. (Volgograd, 2003)

48. L. Yelmslev, New in Linguistics 1, 39-45 (1960) 